\title{
THE
}

2018

\section{Teaching intersectionality: Pedagogical approaches for lasting impact}

Melissa Villa-Nicholas

University of Rhode Island, mvnicholas@uri.edu

Follow this and additional works at: https://digitalcommons.uri.edu/lsc_facpubs

The University of Rhode Island Faculty have made this article openly available.

Please let us know how Open Access to this research benefits you.

This is a pre-publication author manuscript of the final, published article.

Terms of Use

This article is made available under the terms and conditions applicable towards Open Access Policy Articles, as set forth in our Terms of Use.

\section{Citation/Publisher Attribution}

Villa-Nicholas, M. (October 2018) "Teaching Intersectionality: Pedagogical Approaches for Lasting Impact."Education for Information. 34.2

Available at: http://dx.doi.org/10.3233/EFI-180191

This Article is brought to you for free and open access by the Graduate School of Library and Information Studies at DigitalCommons@URI. It has been accepted for inclusion in Graduate School of Library and Information Studies Faculty Publications by an authorized administrator of DigitalCommons@URI. For more information, please contact digitalcommons-group@uri.edu. 
Title: Teaching Intersectionality: Pedagogical Approaches for Lasting Impact Author: Melissa Villa-Nicholas

Assistant Professor

P (401) 874.4714

mvnicholas@uri.edu

Graduate School of Library and Information Studies

University of Rhode Island

Rodman Hall

94 West Alumni Avenue

Kingston, RI 02881

\begin{abstract}
Recently there have been calls to study and apply critical theory and tools around social justice, and intersectional approaches of race, anti-racism, gender, sexuality, disability and accessibility, and class in Library and Information Studies (LIS). But applying lasting techniques in the LIS classroom require pedagogies that are intersectional, assessable, and apply lasting change for the student. This article argues for impactful approaches to intersectionality- the inclusion of multiple identities and subjectivities such as race, gender, sexuality, and class- to LIS in three parts: (1) Teaching critical theories alongside traditional LIS texts, (2) using systems of assessment for cultural competencies and analysis, and (3) classroom activities that implement metacognitive change. These approaches in the LIS classroom can demonstrably move LIS students into a deeper critical analysis of power in libraries that will be applied throughout their careers.
\end{abstract}

Keywords Critical pedagogies, intersectionality, social justice 


\section{Introduction}

The current author has been teaching the course Multiculturalism in Libraries as an elective for Library and Information Studies (LIS) graduate students. Over the years, the author has observed that while students are eager and nervous to jump into to discussions around race, racism, gender, sexuality, class, ability, and ultimately discussions of power in LIS, they have often begun the course with a 'colorblind' mentality- the worldview that one 'does not see race'- that signals cultural immaturity, and while they engage throughout the semester on the course materials, some students revert back to the belief that the 'colorblind' approach is the answer to equality in the library setting. According to clinical psychologist and Associate Proessor Monnica Williams of University Connecticut, colorblindness is "the racial ideology that posits the best way to end discrimination is by treating individuals as equally as possible, without regard to race, culture, or ethnicity...it ends and operates as a form of racism" [1].

The goal for this course is to shift student perspectives, or world views, so that they are culturally competent and apply analysis around power throughout their careers. For the purpose of this class cultural maturity echo's the Association of College \& Research Libraries (ACRL) definition of cultural competence (based on the National Association of Social Workers) as:

A congruent set of behaviors, attitudes, and policies that enable a person or group to work effectively in cross-cultural situations; the process by which individuals and systems respond respectfully and effectively to people of all cultures, languages, classes, races, ethnic backgrounds, religions, and other diversity factors in a manner that recognizes, affirms, and values the worth of individuals, families, and communities and protects and preserves the dignity of each (National Association of Social Workers, 2001) [2]

The foundation for the course is laid out in two ways: by helping students understand that we cannot talk about 'diversity' and 'multiculturalism' in LIS without discussing power and intersectionality. Intersectionality is defined as " the interlocking oppressions of race, gender, 
and class: $[3]^{1}$. Second, we focus on seeing our worldview on intersectionality, and ultimately cultural competencies, as one that is not fixed, but moveable. Identity and power shifts over time and space, therefore we should view intersectional cultural competencies as something that we can both improve and constantly revise.

A transformative pedagogical framework first prioritizes information contexts of power and privilege, and then seeks to shift the student's worldviews into an adaptive mindset that understands and articulates complex systems around race, gender, sexuality, nation, age, ability, language, and citizenship (hereafter referred to as intersectionality). Critical theorist Sharon Patricia Holland [4] notes that these experiences are lived in quotidian acts and choices. Therefore, they must be interrupted with classroom lessons that incorporate more of the embodied senses in which identities and structural hierarchies are experienced.

This article advocates for three parts to intersectional cultural competencies in LIS pedagogy: 1) adapting a critical theoretical intersectional framework to the LIS classroom; 2) using measurable pedagogical tools for assessment in cultural competencies; and 3) using interactive classroom assignments to teach about race, racism, gender, sexuality, class, and ability in the LIS classroom. By using verbal and audio practices, students can cognitively process and adapt intersectional theories and move further into cultural competencies. The goal of this work is for

\footnotetext{
${ }^{1}$ Patricia Hill Collins notes that power and oppression must realize and recognize a 'matrix of domination' in order to move away from one dimensional views of different individuals and groups, and understand that each individual stands at a unique social position of race, class, gender, sexuality, ethnicity, nation, and age (Collins, 2000, p. 299). I amend Collins' work to include ability, language, and citizenship as these are pertinent to library users' identities.
} 
LIS students to shift into an adaptive culturally competent mindset and awareness that will continue to change in their work in libraries.

\section{Literature Review}

\subsection{LIS encourages social justice in education}

LIS literature has seen an upsurge of encouraging intersectional approaches of social justice, diversity, and inclusion into LIS education, especially in light of the 2016 presidential elections and targeting of people of color and LGBTQ by the presidential administration. Previous work on pedagogies in LIS have advocated for critical approaches that include social justice, theory around whiteness and race, and diversity and inclusion of intersectional identities.

Tang et al. [5] encourage teaching diversity and inclusion in the LIS curriculum through documenting relevant resources that can be incorporated into LIS education.

Punzalan and Caswell [6] explore the history of social justice within the archival literature and how social justice can be applied to advance the field. In her work on dismantling white supremacy in the archives, Caswell discusses how she integrates defining white supremacy and how it impacts archives. In order to dismantle white supremacy in the archives, Caswell [7] demonstrates how to use Peggy McIntosh's “White Privilege: Unpacking the Invisible Knapsack" as a base for an activity to teach white privilege, and dismantling white supremacy, to LIS students. Gibson and Hughes-Hassell [8] advocate building students' theoretical foundations around power and social structures in the U.S. and in LIS, in order to prepare them for professional practices of librarianship and careers in information science, noting that it's imperative to focus on marginalized voices within LIS and in the libraries, encouraging LIS educators and professionals that they must take a public role in speaking out against social inequalities. Identity is also a critical part of discourse in the discussion of intersectionality and 
social justice in LIS. Hackney et al. [9] use a qualitative and quantitative methods to visualize how identity terms around gender and sexuality are generalized and rarely crosses into the application of theory into practice.

\subsection{Theoretical Underpinnings: Intersectionality in LIS}

This essay encourages multiple theoretical frameworks for LIS instructors to teach intersectionality. Because race and racism has been deeply embedded in identity and structural institutions in the United States, traditional textual approaches to applying a critical framework around race and racism in LIS fall short of embedding a critical consciousness in LIS graduate students.

Researchers in LIS have found that race and racism are often not discussed among librarians and library studies students, with the terms 'diversity' and 'multiculturalism' as a long intentional stand in for talking about race and racism. LIS scholar Todd Honma interrogates the history of librarianship by finding that the LIS field privileges Western, White, male, middle-class, heterosexual values [10]. LIS scholar Christine Pawley has also argued for making visible race and whiteness in LIS, and that LIS shifts away from an attitude of 'colorblindness' to a cultural awareness of the ways in which race and racism structure libraries and the field of LIS [11]. In response to a field that has been constructed by whiteness and has taken a colorblind approach to power and privilege, Safiya Noble and Sarah Roberts advocate for a social justice framework, noting that, "social justice and diversity are directly linked to liberation from systemic, oppressive racism and gender disparity, which are critical, intersectional, social problems in the U.S. and beyond, and that the ALA core values and Key Action Areas are an important foundation for LIS educators" [12]. 
Intersectionality is a term first created by black legal scholar and Professor Kimberlé Crenshaw in 1989, in order to view multiple oppressions experienced in identity. Crenshaw's work builds on black women's identity through a black feminist framework that encourages an analysis of racism and gender intersect [13]. Patricia Hill Collins later extended these intersections to her metaphor of a matrix of domination, in which she adds multiple layers of race, gender, class, sexuality, nationalism, and age [14]. Language, citizenship, and disability and accessibility are also major parts of intersectionality that are relevant to librarianship, however race is forefronted as an underlying structure that must be included in weekly reflection in the course.

The foundation for this course must include this critical framework that seeks to make racism and intersectionality visible in LIS and to teach LIS students to value social responsibility and diversity, through social justice praxis, action, and advocacy. LIS education around multiculturalism and diversity without foundations of theory and research that have been done around race and racism are devoid of context and therefore give students a shallow understanding of cultural competencies. From there, students can learn about intersectionality of gender, sexuality, class, and ability.

Race, racism, gender, sexuality, disability, class, and citizenship status are lived and reproduced not only structurally and institutionally, but experienced on a daily basis. Those who experience these intersectional identities daily often see systems of discrimination and bias visibly. Those who do not experience these identities or intersections may not see the visibility of oppression, because their own identity and world view tells them otherwise. Cultural assessments and metacognitive assignments are necessary supplements for students to understand these identities 
on a deeper level. A larger objective in this pedagogical approach is for students to see their own progress on a metacognitive level for "the practice of drawing from both cognitive and affective information and acting intentionally on the information through the processes of synthesis and evaluation" [15].

\section{Assessment}

\subsection{The Intercultural Developmental Continuum as a Measurement Tool}

It can be difficult to measure success in cultural competencies when talking about race, racism, and intersectionality. Over multiple semesters, students enter LIS at a different range of cultural understandings and awareness around intersectionality. Some students are eager to discuss race and racism in LIS as they have not had the opportunity to previously do so; some students are surprised that they will be discussing topics around race, racism, sexuality, and gender in a course labelled 'multiculturalism'; and some students come into the course stating very clearly that they hold a 'colorblind' attitude about race, that they do note see race, and this worldview has helped them solve the problem of racism. There are many mindsets that enter into a course on introduction to diversity and multiculturalism. In order to shift students' mindsets towards a culturally competent outlook on race and racism, LIS educators must have a gauge or assessment tool.

The Intercultural Development Continuum (IDC) is one tool that may be helpful to LIS as a field in need of more cultural competencies. While not the only tool for cultural competencies, the IDC is helpful in measuring a student's progress in cultural awareness and maturity. The IDC 
was developed by the Intercultural Development Inventory (IDI), a company that offers intercultural conflict and conflict resolution trainings. ${ }^{2}$

\subsection{The Intercultural Development Inventory}

The Intercultural Development Inventory

“describes a set of knowledge/attitude/skill sets or orientations toward cultural difference and commonality that are arrayed along a continuum from the more monocultural mindsets of Denial and Polarization through the transitional orientation of Minimization to the intercultural or global mindsets of Acceptance and Adaptation" [16].

The IDC includes the following mindsets as a progression, from the monocultural mindset toward an intercultural mindset. These stepping stones have been adapted for LIS relevancy:

- Denial: The Denial Mindset includes a disinterest in other cultures, it does not see difference as cultural. The Denial Mindset also avoids cultural difference, and has a background in monoculturalism. It promotes stereotypes of the 'other' out of inexperience and maintains distance from different cultures. Denial in the library ignores cultural diversity

- Polarization: The Polarization mindset promotes cultural superiority in one group. Cultural difference is seen as a threat to one's own cultural practices. Polarization in the library and LIS field leads to diversity work causing discomfort, it also leads to the promotion of culturally dominant groups through rules, regulations, programming, collections, and especially employment in the library.

\footnotetext{
${ }^{2}$ This is a private company that offers paid cultural competence products, their IDC is one scale that can be considered for educators in understanding and applying movement of awareness and sophistication around race and racism.
} 
- Minimization takes the 'colorblind' approach to culture, it highlights only similarity and universalism around cultures that avoids a deeper understanding of difference. In the LIS setting, minimization leads to students and librarians claiming to be 'colorblind' while ignoring structural discriminations and cultural difference.

- Acceptance: Acceptance and adaptation are both intercultural mindsets that we can work towards and move LIS students towards as measurable mindset in cultural competency. Acceptance adapts a curious mindset that appreciates cultural difference. ${ }^{3}$

- Adaptation: According to IDI, adaptation shifts a person's cultural perspective and enables deep connections across cultures by allowing commonalities and difference. In LIS, the adaptation mindset will celebrate cultural difference [17].

The IDC is a measure in cultural competencies. It gives clear standards for maturing a worldview in embracing cultural difference. However it lacks the depth needed to also apply intersectional critical theories that help students analyze power in library institutions.

\subsection{Bloom's Taxonomy}

While the IDI is helpful for cultural competencies, it neglects a deeper critical analysis around power structures in the United States. We can bring in Bloom's Taxonomy as a measurement tool for bringing cultural competencies into a more sophisticated approach to power and hierarchy in LIS. Bloom's Taxonomy is a framework for categorizing educational goals and assessing matured educational levels. Invented by Benjamin Bloom in 1956 with education

\footnotetext{
${ }^{3}$ IDI's own description of 'acceptance' uses only two genders to describe people's place in this process. This interestingly points to the 'denial' framework that ignores the language of multiple genders.
} 
collaborators, Bloom's Taxonomy has been revised by psychologists, curriculum theorist and instructional researchers to be knowledge based in the cognitive process [18]. In LIS, Bloom's taxonomy can help us assess our own understanding of cultural competencies and intersectionality and the surrounding structures of hegemony that shape LIS. For example, we want to move LIS students and professionals from a place of remembering and understanding the text, to analyzing, evaluating, and ultimately creating (producing new work).

In applying intersectionality to Bloom's Taxonomy, we can view assessment and progress of a student's understanding, adapting, and maturing to intersectional concepts in the following framework in Figure 1.

\section{Classroom Activities}

Analyzing intersectionality (race, racism, gender, sexuality, ability and accessibility) from a critical standpoint is a habit and skill that students must engage in consistently throughout the semester, and apply to their careers. When LIS students do not experience difference on an everyday basis, the lens of cultural awareness can easily be forgotten for more practiced belief systems. For example, in Multiculturalism in Libraries the few students that start with the 'I'm colorblind I don't see race' framework will learn throughout the semester why this framework is not a viable approach for librarianship. They watch videos, read, listen to lectures, and discuss difference on why colorblind is not a feasible approach in the United States. However, at the end of each semester, some students will return to 'colorblind' as a response to power structures that impact the library. With these observations in mind, the powerful normative habits of everyday 
lived experiences must be broken with classroom activities that can act as a practice to break habits of normativity.

Using the above framework, this lesson engages students' active learning in order to improve mastery over the concepts of intersectional power in LIS, to improve long term retention of these skills of analysis, and to increase problem-solving from a critical perspective [19].

At the beginning of the semester, students should be given the IDC to study and identify their own cultural competencies on the spectrum. At the end of the semester, students should reevaluate their own world view about culture and note if any perspectives have changed. Instructors can use the student's self-assessment of the IDC and Blooms Taxonomy to observe if students have advanced in their own understanding of cultural competencies and intersectionality. ${ }^{4}$

The following three activities work to build the three objectives of this course: Student led webinars are used to adapt critical theories around power into the field of LIS; 'Speed Interviewing' works to improve student's mastery over analysis and connect LIS intersectionality to their everyday lives; and auditory/video journaling is used for students to assess their own personal progression on topics covered throughout the semester.

\footnotetext{
${ }^{4}$ Refer to Blooms Taxonomy for evaluation. Students should exhibit a move from the rudimentary ability to remember and understand material on intersectionality, into a more advanced system of building new theories and programming of LIS with the understanding of structural race and racism, evaluating libraries and librarianship based on how it is formed by intersectional systems of power, and theorizing their own ideas around power and LIS. See Armstrong, Patricia's examples of Bloom's Taxonomy at the Vanderbilt Center for Teaching https://cft.vanderbilt.edu/guides-sub-pages/blooms-taxonomy/
} 


\subsection{Webinars}

\section{Outcomes}

- To adapt a critical pedagogy in LIS instruction

- To demonstrate the student understands and retains complex analysis of power in society

Librarianship in the United States has long been a racially white field, and constructed around whiteness. Libraries, library associations, patrons, academics have both demanded and attempted to bring to light and change this diversity gap [19]. This pedagogy must continue to prioritize race and racism while focusing on other intersections. Critical academic articles on whiteness, critical race theory, or cultural studies that anchor students to new theories around structural racism each week, alongside other intersections (gender, sexuality, class, ability, citizenship). Students are then given prompts to draw out of the article and give audio/visual presentations on a particular critical theory (See Appendix A).

Building on Doyle's concept of "he who does the work does the learning" [20], these exercises transcribes critical theories from text to audio. Using audiovisual tools, students must prepare a webinar that demonstrates their ability to articulate and describe critical theory concepts to their classmates. This encourages students to learn the course material from each other and ensures that students are not solely consuming and rewriting text, but processing critical theories visually and audibly. In IDC, this exercise attempts to move students from a 'denial' mindset around race and racism into 'acceptance', however it does not move students beyond 'remembering' and 'understanding' the material in Bloom's Taxonomy. 
Instructions:

1. At the beginning of the semester, assign students an article that is based in understanding critical theories around race, class, gender, sexuality, ability, and citizenship

2. Student will create an 8-10 minute video using a visual tool (PowerPoint, Prezi, Haiku Deck, etc) and screencast the lecture so that its shareable in a link

3. Student's must summarize their audio/visual lecture around the texts: Main point, context, kinds of reasoning (concepts, theory, methodology), evidence (statistical, literary, historical, primary, secondary), evaluation (is there a criticism that can be applied?), quotes from the article, and questions that the student developed from the article

4. Students will present their webinars week to week throughout the semester, leading course discussion with their reading questions

\subsection{Speed Interviewing Critical Theory}

\section{Objectives}

- To use educational tools for measuring cultural competencies

- To advanced students into a more mature cultural competence and analysis of intersectionality in LIS through speaking and listening practices Speed Interviews is an 'Intentionally Designed Educational Activity' specifically created with the intent of improving student's mastery over material that they are otherwise unfamiliar with, and to relate this information to prior knowledge [21]. Students must first read articles based on 
intersectionality in LIS (See Appendix B for critical articles that can be used as prompts).

Students must come to class with three questions drafted about the content of that article, and three questions that engage how the student relates their own lives to the topic.

The objective of this exercise is to move students beyond 'understand' and 'remember' into 'apply and 'analyze' in Bloom's Taxonomy. This activity is important to engage with on a biweekly basis, or staggered throughout the semester.

Instructions:

1. The instructor has students gather in pairs (formed as if they are 'speed dating'), or if the discussion is online, sets up discussion rooms to bring student's in and out of to rotate the conversant (this is dependent on the technology platform used for online learning).

2. Students will have 3-5 minutes each to ask each other a question and listen to their peer's response with no interruption, and then move onto the next question. Asking each peer 3 questions about that topic.

3. Students will rotate around the room to interview each other quickly about the readings with new questions.

\subsection{Auditory and/or Video Journaling}

Objectives: 
- Students will adapt a metacognitive awareness of their own cultural competencies growth

- Students will relate the concepts around power in LIS to their own lives

The use of audio and video journaling after this assignment works in two ways: First, to move students from remembering and understanding information about intersectionality and race and racism, into analysis, assessment (evaluate), and eventually to 'theorize' (create) their own ideas around power. In the IDC, this exercise attempts to make student conscious of their own cultural mindset, and aware of their movement along the continuum into cultural maturity. To measure a shift in LIS students from the 'remembering' and 'understanding' of the material around race and racism (such as how racism discriminates against rights to fair housing and education), and toward 'creating', or theorizing about race and racism in library settings, is an end goal because it demonstrates that students have retained the materials completely, and can move into the library setting ready to 'create' new solutions for structural discriminations in the library. Second, this activity seeks to embed topics of intersectionality beyond the textual, through reflection. Adult learners find the most value in activities that have relevance to their personal lives. This quick activity, when done weekly, has students connect the materials to their personal lives [22].

Because all LIS students might not experience all aspects of intersectional identity, their everyday lived experience must be challenged in order to move up on Bloom's Taxonomy, and across the IDC.

Instructions: 
1. Students will use audio and/or video journal entries throughout the semester to process the material consistently at the beginning and end of the week. Students should audio/video journal for a limited time, no more than 3 minutes at the beginning of the week, answering one of the following prompts:

- What do you know about the topic?

- How does the topic this week relate to your life?

- What do you know about how the topic impacts libraries?

- What are some unknowns going into this week?

- How do you feel as a student going into this topic?

2. At the end of the week, after the lesson and discussions, students must audio/video journal again for 3 minutes, and can use the following prompts:

- What were your experiences with the course content?

- How are you situated in relation to the material this past week?

- How do you feel as a student now?

3. Students submit files at the end of each week as private assignments that will be reviewed by the instructor.

4. At the end of the semester, challenge students to listen to 5-10 submissions at the beginning and the end of the semester to observe their own shifting world view.

5. Challenge students to map or draw their own shifting lens around the topics of intersectionality and LIS.

\section{Conclusions}

This paper argues that assessment and evaluation must be implemented when teaching racism in 
LIS. Moving into an advanced understanding of race, racism, gender, sexuality, class, and ability is critical in improving the field of LIS and creating egalitarian library spaces. Instructors in LIS can encourage a more culturally competent student that is training for the library and information professions by first laying a theoretically advanced basis around race and racism, identifying the ability to assess cultural competencies through tools such as the IDC and Blooms Taxonomy, and applying classroom activities to make a lasting impact on students' world views that will stay with them beyond their MLS degree.

More work must be done to identify how LIS pedagogy can train students, instructors, and information professionals' growth, so that they adapt the skills needed to create a culturally competent library. Future scholarship will include data collection in multiple courses that teach intersectionality and LIS, and a follow up on students as they transition into librarianship, to observe and assess which pedagogical approaches 'stuck' and which need improvement. The end goal for this work is to create anti-racist, anti-sexist spaces that celebrate gender and disability diversity in the library, and create a ripple effect among communities.

This study hopes to contribute to the ongoing conversation about teaching race, gender, sexuality, and all intersections of identity. This pedagogical conversation can go beyond the U.S. context, and beginning a conversation on how to teach power and intersectionality in LIS outside of the U.S. would be a welcome exchange to help improve egalitarian educational outcome.

\section{Acknowledgements}

Special thanks to the editors and reviewers for your comments and help in improving this article. 
Appendix A: Works on race, racism, gender, sexuality, class, disability, and citizenship in the United States

Ahmed S. On Being Included: Racism and Diversity in Institutional Life. Durham: Duke University Press; 2012 .

Brown, M. Whitewashing race: the myth of a color-blind society. Berkeley and Los Angeles: University of California Press. 2005.

Collins, P.H. Black feminist thought: Knowledge, consciousness, and the politics of empowerment. Boston: Unwin Hyman; 1990.

Harvey, D. A brief history of neoliberalism. Oxford: Oxford University Press; 2007.

Harris C. Whiteness as property. In: Crenshaw, K, editor. Critical race theory: The key writings that informed the movement. New York: The New York Press; 1995.

Ridgeway C, \& Correll S. Unpacking the gender system: A theoretical perspective on gender beliefs and social relations. Gender and Society. 2004; 18(4): 510-31.

Titchkosky T, \& Aubrecht K. The anguish of power: Re-mapping mental diversity with an anticolonial compass. In: Kempf A, editor. Breaching the colonial contract: Anti-colonialism in the US and Canada. New York: Springer; 2009. p.179-201. 
Appendix B: Works on Intersectional Applications in LIS

Austin, J. Critical issues in juvenile detention center libraries. The Journal of Research on Libraries and Young Adults. 2012. http://www.yalsa.ala.org/jrlya/2012/07/criticalissues-in-juvenile-detention-center-libraries/

Doherty J. No shhing: Giving voice to the silenced: An essay in support of critical information literacy. Library Philosophy and Practice (e-Journal). 2007; June: 133.

Drabinski E. Queering the catalog: Queer theory and the politics of correction . The Library Quarterly. 2013; 83(2), 94-111.

Dunbar, A. Introducing critical race theory to archival discourse: getting the conversation started. Archival Science. 2006; 6, 109-129.

Elmborg J. Critical information literacy: Implications for instructional practice. The Journal of Academic Librarianship. 2006; 32(2): 192-199.

Hall, T. D. Race and place: A personal account of unequal access. American Libraries. 2007; $38(2), 30-33$.

Honma, T. Trippin' over the color line: The invisibility of race in library and information studies. InterActions: UCLA Journal of Education and Information Studies, 2005; 1(2).

Krebs, A. Native american's 21st century right to know. Archival Science. 2012; 12(2)

Maack M N. Gender, culture, and the transformation of american librarianship, 1890-1920. Libraries \& Culture. 1998; 33(1), 51-61.

Malone, C K. Autonomy and accommodation: Houston's colored carnegie library, 1907-1922. Libraries \& Culture, 1999; 95-112. 
O’Neal, J. The right to know': Decolonizing native american archives. 2015; 6(1).

Pawley, C. Unequal legacies: Race and multiculturalism in the LIS curriculum. Library Quarterly. 2006; 76(2), 149-169.

Roberts, S T and Noble, S U. Empowered to name, inspired to act: Social responsibility and diversity as calls to action in the LIS context. Library Trends. 2016; 64(3); 512-532. 


\section{Works Cited}

[1] Williams, MT. Colorblind ideology is a form of racism. Psychology Today; 2011. December 27, 2011. Available from https://www.psychologytoday.com/us/blog/culturallyspeaking/201112/colorblind-ideology-is-form-racism

[2] National Association of Social Workers. Standards and indicators for cultural competence is social work practice. Washington, DC: National Association of Social Workers; 2015. Available from https://www.socialworkers.org/LinkClick.aspx?fileticket=PonPTDEBrn4\%3D\&portalid=0 [3] Collins, PH. Black feminist thought: Knowledge, consciousness, and the politics of empowerment. Boston: Unwin Hyman; 1990. 287.

[4] Holland, SP. The erotic life of racism. Durham, N.C: Duke University Press; 2012.

[5] Tang, R, Adkins, D, Ceja, J, Cooke, N, Fogle, Kurz, R, Salvatore, and C, Saunders, L. Diversity in LIS education resources, Journal of Education for Library and Information Science; 2017; 58(4): 241-244.

[6] Punzalan, RL and Caswell, M. "Critical directions for archival approaches to social justice," The Library Quarterly; 2016; 86(1): 25-42.

[7] Caswell, M. Teaching to dismantle white supremacy in archives. The Library Quarterly; 2017; 87(3): 222-235.

[8] Gibson, A and Hughes-Hassell, S. We will not be silent: Amplifying marginalized voices in LIS education and research," The Library Quarterly; October 2017; 87(4): 317-329.

[9] Hackney, SE, Handel, D, Hezekiah, B, Hochman, J, Lau, A, and Sula, CA. Visualizing identities in LIS literature. Journal of Education for Library and Information Science; 2018; 59(1-2): 10-32.

[10] Honma, T. Trippin' over the color line: The invisibility of race in library and information studies. InterActions: UCLA Journal of Education and Information Studies; 2005; 1(2). Available from http://escholarship.org/uc/item/4nj0w1mp [11] Pawley, C. Unequal legacies: Race and multiculturalism in the LIS curriculum. Library Quarterly. 2006; 76(2), 149-169.

[12] Roberts, ST and Noble, SU. Empowered to name, inspired to act: Social responsibility and diversity as calls to action in the LIS context. Library Trends. 2016; 64(3); 512-532. 
[13] Crenshaw, K. Demarginalizing the intersection of race and sex: A Black feminist critique of antidiscrimination doctrine, feminist theory, and antiracist politics. University of Chicago Legal Forum, 1989, 139-67.

[14] Collins PH, Black feminist thought: Knowledge, consciousness, and the politics of empowerment, second edition (New York: Routledge, 2001), 11-12.

[15] Major, C.H, Harris, MS, Zakrajsek, T. Teaching for learning: 101 intentionally designed educational activities to put students on the path to success. Routledge. New York and London. 2016; 291.

[16] Intercultural Development Inventory. The Intercultural Development Continuum (IDC). 2018. Available at https://idiinventory.com/products/the-intercultural-development-continuumidc/\#

[17] Ibid.

[18] Armstrong P. Bloom's taxonomy. Vanderbilt University. 2018. Available from https://cft.vanderbilt.edu/guides-sub-pages/blooms-taxonomy/

[19] Major et al., p. 118.

[20] Doyle, T. Learner-centered teaching: Putting the research on learning into practice. Sterling, VA: Stylus. 2011.

[21] Hathcok, A. 2015. White librarianship in blackface: Diversity initiatives in LIS. In the Library with the Lead Pipe. Accessed http://www.inthelibrarywiththeleadpipe.org/2015/lisdiversity/ . Also See: Bourg, C. (2014, March 3). The unbearable whiteness of librarianship. Feral librarian. [Blog post]. Retrieved from https://chrisbourg.wordpress.com/2014/03/03/the-unbearable-whiteness-of-librarianship. [22] Major et al., p. 229 